\title{
Identifying and disrupting problematic implicit beliefs about engineering held by students in service-learning
}

\author{
David A. Delaine \\ Department of Engineering Education \\ Ohio State University \\ Columbus, $\mathrm{OH} 43210$ \\ delaine.4@osu.edu \\ Renee Desing \\ Department of Engineering Education \\ Ohio State University \\ Columbus, OH 43210 \\ desing.3@osu.edu \\ Emily Dringenberg \\ Department of Engineering Education \\ Ohio State University \\ Columbus, OH 43210 \\ dringenberg.1@osu.edu \\ Linjue Wang \\ Department of Engineering Education \\ Ohio State University \\ Columbus, OH 43210 \\ wang.10961@osu.edu \\ Joachim Walther \\ College of Engineering \\ University of Georgia \\ Athens, GA 30602 \\ jwalther@uga.edu
}

Abstract - Service-learning (SL) is a promising way to engage and support local communities, educate students as holistic citizens and professionals, and strengthen the connection between higher education and society. However, within engineering education, SL as a pedagogy often falls short of reaching its full potential as a transformational pedagogy. To further our understanding of why SL, in the context of engineering, remains limited, this research characterizes: 1) implicit beliefs about engineering in students' descriptions of their SL experiences, and 2) the ways in which students' beliefs manifest within the context of SL in engineering. Our data include rich, contextual descriptions of SL experiences, which enabled us to generate insight into students' implicit beliefs about engineering and how they manifest in SL contexts. We used an inductive, qualitative approach to analyze focus group and interview data. We found that students predominantly draw on three implicit beliefs about engineering when engaged in SL experiences: (1) Engineering is predominantly technical, (2) Engineering requires deliverables or tangible products, and (3) Engineers are the best problem solvers. These beliefs often manifested problematically, such that they promote university-centered and apolitical SL practice, while reinforcing social hierarchy, leading to community exploitation in support of student development. This study produces empirical evidence that such implicit beliefs are a mechanism that limits the potential of SL by hindering community-centric and justice-oriented practice. However, some students demonstrated their ability to disrupt these beliefs, thereby showing the potential for SL as a pedagogy in engineering to surface implicit and counterproductive beliefs about engineering and achieve SL goals. The beliefs that are salient in SL and the concrete ways in which they manifest for students have implications for how SL is practiced in engineering and the experiences of both students and partner communities. These beliefs impact the extent to which the socio-political elements of the service are addressed, the extent to which SL is 
International Journal for Service Learning in Engineering, Humanitarian Engineering and Social Entrepreneurship Vol. 16, No. 2, pp. 14-38, Fall 2021

ISSN 1555-9033

university- versus community-centric, and the quality and extent to which the engineering solution is aligned with social justice. The implications of these findings lead to recommendations for future research on how engineering educators might explicitly design SL curricula to identify, address, and dismantle problematic beliefs before they manifest in problematic ways in SL contexts.

Index Terms - implicit beliefs, qualitative research, service-learning, undergraduate

\section{INTRODUCTION}

Service-learning (SL) has the power to be a positive vehicle for change, impacting both the students and the community. SL has been recognized as a high impact educational practice ${ }^{1}$ that can prepare students to work in a wide variety of contexts and with a wide variety of people, while mitigating challenges in local communities. ${ }^{2,3,4}$ Because of this potential, SL has proliferated broadly across higher education, ${ }^{5}$ and while SL is now well-established in engineering education, ${ }^{6,7,8}$ it is often peripheral or supplementary to degree granting curricula.

Through SL, undergraduate engineering students can gain additional skills beyond their major coursework, such as professional skills and relationship building, while the community may benefit from the products and services developed with students. Within engineering education, practitioners and researchers often focus on SL's ability to offer real-world, hands-on applications of engineering skills: SL often positions students within resource-constrained communities to collaboratively develop an engineering solution for a community need. ${ }^{9}$ However, such practice can become problematic: without careful preparation and an intentional approach, students may develop skills while the community is exploited and patronized, ${ }^{10}$ and SL might exacerbate the injustices/inequities it seeks to address. SL practitioners and researchers intend for the programs to be positive for all stakeholders, but outcomes often fall short of this goal because the field lacks critical research and reflection on the approaches, goals, and outcomes of SL in engineering. Researchers have previously identified several problematic elements of SL, including its tendency to reinforce social hierarchy and stereotypes, prioritize university outcomes and needs over those of the community, and develop projects misaligned with community needs. ${ }^{11,12}$ By allowing problematic elements of SL to persist in engineering, a lack of critique ultimately limits SL's potential to achieve the promised outcomes for universities, students, and partner communities. ${ }^{13}$ Critique of SL in engineering is necessary to determine the cause of these elements and the pedagogical improvements that can best address them. The problematic elements in SL are often transmitted implicitly; even SL courses that attempt to address the problematic elements often do not always address them explicitly, or in ways that support students' ability to understand and resolve them. To address this gap in SL practice, we need to investigate students' underlying assumptions and implicit beliefs about engineering to better understand how and when these beliefs and assumptions surface, and how SL courses can better teach students how to navigate these problematic elements.

In this research, a qualitative approach was used to critically explore data from interviews where undergraduate engineering students describe their experiences in SL; our aim was to identify students' underlying assumptions and shared implicit beliefs about engineering within SL contexts. Using an analytical coding process, we made sense of students' explicit descriptions by generating themes that are connected directly to what they said, but represent the implicit beliefs 
International Journal for Service Learning in Engineering, Humanitarian Engineering and Social Entrepreneurship Vol. 16, No. 2, pp. 14-38, Fall 2021

ISSN 1555-9033

embedded in their discourse. This process enables us to contribute a critical look at the ways in which implicit beliefs about engineering and engineers in the context of SL may maintain the status quo and prevent SL in engineering from reaching its transformational potential. The way these implicit beliefs are manifested in undergraduate engineering student SL experiences was studied to understand how students' implicit beliefs reflect (1) the limitations of university-centric SL practice that prioritizes student outcomes and (2) the embedded potential of SL pedagogy in engineering to promote transformation toward social justice. We aim to reveal to SL researchers and practitioners the ways in which student beliefs about engineering are manifested, as well as how these beliefs may further the ability of SL to serve as a transformational pedagogy within engineering education.

\section{Literature Review}

Service-learning's potential includes a wide variety of positive outcomes for both students and community partners. Student outcomes often include strengthened professional skills, hands-on abilities, cultural competence, academic and life skill development, and sense of civic/social responsibility. ${ }^{8,14}$ Community outcomes include volunteer efforts and sources of human capital, engineering solutions within the community's areas of need, and educational programming. ${ }^{15,16,17}$ These wide-ranging outcomes provide a foundation for universities to develop civic-minded professionals and provide positive return to society. ${ }^{18,19}$

In addition to these immediate participant-level benefits, SL also has the potential to promote social justice and transformational change. Advances in SL across higher education ${ }^{20,21,22}$ center non-university outcomes and perspectives, and are grounded in pedagogy that prepares students to be active members of a democratic society. ${ }^{23}$ Scholars have established frameworks like critical service learning, ${ }^{24}$ enriched reciprocity, ${ }^{25}$ and democratically engaged partnerships. ${ }^{26}$ These $^{2}$ frameworks articulate SL that promotes deep, mutual outcomes that support lasting positive change to individuals, organizations, and contexts. Within these approaches, students gain critical thinking skills, leadership skills, and learn civic responsibility while communities gain academic partnerships and collaboration opportunities; both groups gain critical consciousness. ${ }^{27,28}$

Essential to these approaches is their emphasis on centering relationships among participants, ${ }^{29,30}$ acknowledging community authority and power in shaping SL goals, approaches, and outcomes, and exploring ways to address the root causes of challenges manifested in SL contexts. ${ }^{24}$ These deeper outcomes ultimately align this type of SL with social justice, which has been operationalized in engineering as "practices that strive to enhance human capabilities through an equitable distribution of opportunities and resources while reducing imposed risks and harms among agentic citizens of a specific community." 16, p. 4 Transformational SL, characterized by the long-term impacts of mutually beneficial partnerships supporting growth of critical consciousness across all partners, ${ }^{31}$ can systematically dismantle the root causes of the social ills requiring the need for SL in the first place. ${ }^{24}$ These transformational outcomes can be equitably distributed across partners through engaging in transformational approaches to partnership ${ }^{32}$ and managing the ways power is manifested in these relationships. ${ }^{10}$ Transformational SL articulates the potential embedded in SL pedagogy.

However, SL within engineering has struggled to consistently align its pedagogy with social justice frameworks and outcomes, ${ }^{16,17}$ and has not kept pace with other disciplines that have adopted these advances, such as medicine, ${ }^{33}$ nursing, ${ }^{34}$ and social work. ${ }^{35,36}$ This lack of alignment has caused SL in engineering to face disciplinary challenges in demonstrating outcomes consistent 
International Journal for Service Learning in Engineering, Humanitarian Engineering and Social Entrepreneurship Vol. 16, No. 2, pp. 14-38, Fall 2021

ISSN 1555-9033

with transformational SL pedagogy: specifically, researchers do not commonly report deeper student learning outcomes, outcomes focused on community partners, or social justice/transformation. These limitations within engineering have led to approaches that researchers in SL have described as "akin to a design problem", where educators "integrate the subject matter of a credit-bearing course with service useful to the community," ${ }^{37, \text { p. } 2}$ rather than orienting outcomes towards social change and empowerment of the community. Outcomes such as civic-mindedness and a sense of social responsibility, which require deep introspection and guided reflection, are less often reported in the engineering literature. While researchers have explored the opportunity for participants to develop cultural competence, ${ }^{12}$ a critical examination of the power imbalances of white students who "serve" an often-marginalized community of Color are not addressed often. ${ }^{38}$ Furthermore, the ways in which SL can promote unintended student learning outcomes with negative impacts, such as reinforcing stereotypes and social hierarchies, are under-examined. ${ }^{10,39}$ Although some SL educators in engineering pursue social justice outcomes and lasting community impact, ${ }^{15,16,17}$, the outcomes rarely include development of solutions that address the root causes of social ills. ${ }^{24}$ The persistence of an engineering SL that centers technical solutions may mean that the outcomes of a transformational SL pedagogy (i.e., the elimination of root causes) remain an aspirational goal for engineering SL. Technical solutions alone may often fall short of the comprehensive approaches required to truly accomplish such elimination. Nonetheless, engineering SL pedagogy can and should seek ways to pursue the potential for transformational SL and ensure that students produce technical solutions informed by an awareness of the root causes of social ills that touch the communities for whom they are intended.

\section{Theoretical Framework: Beliefs}

To explore why SL is not reaching its full potential in the context of engineering, it is useful to employ implicit beliefs as a theoretical framework. Beliefs are a fundamental part of how we make sense of our world and are interwoven with how we behave. ${ }^{40,41,42,43,44}$ In educational contexts, scholars have argued that beliefs are fundamental to teaching, ${ }^{45,46}$ and researchers have shown empirically that engineering students' beliefs correlate with their academic behavior. ${ }^{47}$ For example, the extent to which it is believed that success in a field (including STEM fields) depends on innate intelligence inversely predicts the participation of women and Black people in those fields. ${ }^{48}$ Furthermore, within STEM, the beliefs of educators explain the achievement gap of minoritized students. ${ }^{49}$

In addition to informing our understanding of participation and performance in STEM, beliefs are also a useful theoretical framework to understand engineering. Because beliefs are transmitted via culture, they vary by context and discipline. Beliefs have been shown to vary by academic discipline in higher education. For example, Jehng and colleagues ${ }^{50}$ revealed that students in social science, arts, and humanities have a stronger tendency to believe that knowledge is uncertain and rely more on their own independent reasoning ability than students in engineering and business disciplines. Conefrey ${ }^{51}$ demonstrated how beliefs within science and engineering spaces are a mechanism through which gender discrimination is perpetuated, even when these beliefs remain implicit (e.g., meritocratic beliefs). Researchers have also provided evidence for how beliefs about what it means to be smart are discipline-specific. ${ }^{52,53}$

Our most powerful beliefs are often implicit. In fact, implicit beliefs are understood to be a key aspect of how our broader socialization ensures the maintenance of the status quo. ${ }^{51,54,55,56,57}$ 
Within engineering education, $\mathrm{Cech}^{58}$ has argued persuasively that the underlying cultural beliefs that engineering is apolitical and meritocratic inherently limits the field. Walther and colleagues ${ }^{59}$ show how students' assumptions (synonymous with beliefs in this context) about ways of being engineers were critical for their ability to develop and embody empathic skills. For example, students espouse a belief in the value of empathic approaches to making design decisions, but they report behaving in ways that contradict that espoused belief, ${ }^{60}$ suggesting the importance of investigating beliefs that operate outside of conscious awareness: implicit beliefs influence what we do and how we do it. Implicit beliefs held by students were shown to have consequences for the ways in which students engage with communities during service-learning projects, ${ }^{61,62}$ yet knowledge of student beliefs about engineering in SL contexts remains limited.

We used beliefs as a lens to understand and characterize the limitations that prevent SL from reaching its full potential within the context of engineering. Beliefs are complex, often inconsistent or contradictory, and can be formed passively and without reflection. ${ }^{44,56}$ As such, beliefs can exist at different levels of awareness - espoused beliefs are what one is aware of and can state explicitly; implicit beliefs operate outside of conscious awareness. ${ }^{40,44}$ Implicit beliefs are most appropriate for our use in this study because it is those beliefs - which students do not demonstrate conscious awareness of - that can prevent SL from reaching its full potential as a pedagogical method in subliminal ways, as opposed to explicit beliefs that an instructor can more easily recognize and address. Therefore, our analysis operationalizes beliefs as implicit rather than explicit or espoused. By using this theoretical framework to surface and understand what implicit beliefs manifest in students' descriptions of their experiences with SL, we can progress towards SL reaching its full potential.

\section{Research Questions}

Based on the reviewed literature and our theoretical framing, our study was guided by the following research questions: (RQ1) What beliefs about engineering are implicit in undergraduate engineering students' descriptions of their SL experiences? and (RQ2) How do these beliefs manifest in engineering SL experiences?

\section{METHODS}

This qualitative study used an interpretivist paradigm ${ }^{63}$ to collect and analyze undergraduate engineering students' SL experiences. Specifically, focus groups and individual interviews were conducted with students after they completed a SL experience. To explore a variety of student experiences, students were recruited from multiple SL offerings available at a large midwestern university, where each offering is tied to engineering, for-credit coursework and included a direct "service" element for a specific community. The ways in which students discussed their experiences in SL were analyzed to understand students' implicit beliefs about engineering and how those beliefs manifested in and impacted their experiences in engineering SL.

\section{Data Collection}

The data used in this study were selected from a larger project which explores the ways engineering students develop empathy in community-based learning contexts in a large midwestern university (NSF \#1821866). From that study, four for-credit, SL cases were selected to center the findings of 
International Journal for Service Learning in Engineering,

Humanitarian Engineering and Social Entrepreneurship

Vol. 16, No. 2, pp. 14-38, Fall 2021

ISSN 1555-9033

this paper (described in Table I). All data were collected following institutional review board (IRB) approved protocols.

\section{TABLE I}

DESCRIPTION OF THE FOUR SL CASES

\begin{tabular}{|l|l|l|}
\hline \multicolumn{1}{|c|}{ SL Case } & \multicolumn{1}{|c|}{ Activity Description } & \multicolumn{1}{c|}{ Time Commitment } \\
\hline Domestic Garden & $\begin{array}{l}\text { A domestic service-learning course that } \\
\text { takes place in a mid-western state, working } \\
\text { to minimize local food deserts in } \\
\text { partnership with a local non-profit. }\end{array}$ & $\begin{array}{l}\text { Around 6-12+ hours of visit across } \\
\text { a semester with additional project } \\
\text { development and design during } \\
\text { class time }\end{array}$ \\
\hline International Orphanage & $\begin{array}{l}\text { An international service-learning course } \\
\text { with a week-long activity in Honduras at } \\
\text { an orphanage for youth affected by HIV. }\end{array}$ & $\begin{array}{l}\text { 40+ hours across five on-site } \\
\text { workdays with additional project } \\
\text { development and design during } \\
\text { class time prior to travel }\end{array}$ \\
\hline $\begin{array}{l}\text { Domestic Center for } \\
\text { Adults with Special Needs }\end{array}$ & $\begin{array}{l}\text { A volunteer, co-curricular requirement for } \\
\text { humanitarian engineering scholars where } \\
\text { students visit a home for residents with } \\
\text { profound developmental disabilities. }\end{array}$ & 2 hours in one day \\
\hline In-Class Design Challenge & $\begin{array}{l}\text { A co-curricular requirement for } \\
\text { humanitarian engineering scholars where } \\
\text { students design solutions to provide shelter } \\
\text { for homeless people. }\end{array}$ & $\begin{array}{l}\text { 6 hours of in-class time across 3 } \\
\text { weeks }\end{array}$ \\
\hline
\end{tabular}

After the students completed the "service" element of each course, the research team recruited students from each case for a 90-minute focus group. The focus group was used to gather shared experiences of the students through a group discussion. Following the focus groups, one student from each group was selected to participate in a 60-minute one-on-one interview to document their in-depth personal experience. Three selection criteria were used to select each interview student: 1) the individual remained quiet during the focus group, but exhibited body language that indicated engagement in the conversation, 2) the individual showed motivation to share, but was cut off or did not have enough time to elaborate, 3 ) the individual struggled or had challenging experiences during the SL experience. Ultimately, we conducted one focus group and one interview per case. Table II highlights the number of participating students within each case.

TABLE II

SUMMARY OF QUALITATIVE DATA COLLECTION PARTICIPATION FROM FOUR SL CASES

\begin{tabular}{|l|c|c|c|c|}
\hline \multicolumn{1}{|c|}{ Case } & $\begin{array}{c}\text { Domestic } \\
\text { Garden }\end{array}$ & $\begin{array}{c}\text { International } \\
\text { Orphanage }\end{array}$ & $\begin{array}{c}\text { Domestic Center for } \\
\text { Adults with Special } \\
\text { Needs }\end{array}$ & $\begin{array}{c}\text { In-Class Design } \\
\text { Challenge }\end{array}$ \\
\hline Student participants & 8 & 9 & 10 & 70 \\
\hline Focus group & 7 & 7 & 3 & 3 \\
\hline Interview & 1 & 1 & 1 & 1 \\
\hline
\end{tabular}

A semi-structured protocol was used within the focus groups and one-on-one interviews to broadly explore and co-construct the lived experiences of the students' participation in SL. The protocols explored SL experiences through discussions around the SL context, students' feelings and interpretations of their experiences, their interactions with others in the context, as well as the way the experiences reflect on engineering and their own personal and professional development. 
International Journal for Service Learning in Engineering, Humanitarian Engineering and Social Entrepreneurship Vol. 16, No. 2, pp. 14-38, Fall 2021

ISSN 1555-9033

Pseudonyms were used to prevent identification. Further, because of the low number of participants, the demographic information of the entire group is not displayed to protect their privacy; however, certain demographic information is displayed for the excerpts presented to provide context. Incentives for focus group participants included a meal and refreshments; incentives for one-on-one interviewees were $\$ 25$ gift cards.

While the interview protocols were designed for a larger project where empathy development was the central phenomenon of interest, we justify data re-use, aligned with current practices, ${ }^{64}$ to explore the students' beliefs about engineering based on the following criteria: First, the interview protocol started with a broad and general question to allow the students to recall their experience in a way that made sense to them, allowing for the co-constructing of the experience from the participant perspective. This broad question also probed the way that the students made sense of their experiences, which can indicate the beliefs they hold about engineering. For example, students describing the experience as conducting an engineering project and preparing a presentation demonstrate different beliefs than students describing the experience as working with the community on a project. Second, the interview protocol included a set of prompts designed to elicit students' stories about interacting with others. This prompt was intended to explore the way that the students expressed their experiences when they interacted with others in SL. The word choices and phrasing with which students expressed their interactions can reflect their beliefs about engineering in SL contexts. These questions situated the students within the unique context of SL and allowed the students to describe their beliefs about engineering based on how they perceive interpersonal relationships in the context of SL. Lastly, the interview included prompts such as, "how did you feel...?", "what struck you most...?", and "what did you do...?", to follow up with the students' descriptions of their experience. These prompts allowed us to explore the way that the students articulated their feelings, cognitive reflections, and actions taken, indicating the beliefs about engineering through personal accounts. ${ }^{65}$ Overall, beliefs are hard to observe, but they are verbally embedded in the participants' retrieval of their lived experiences. As a result, the discussions of the topics within the protocol were effective in revealing implicit beliefs as well as which beliefs were salient amongst the students.

\section{Data Analysis}

The analysis was performed in two phases: first, holistic coding to explore the data, followed by theming the data to synthesize and organize the themes. ${ }^{66}$ The holistic coding was conducted using the NVivo software, the results of which were exported into a spreadsheet that was then used to theme the data. Holistic coding is a qualitative method that allows for the analysis of large portions of the data in order to develop possible categories in subsequent analyses from an initial set of topics. ${ }^{66}$ Due to the exploratory nature of our study, this approach is appropriate to use as a preparatory stage for analyzing our data. For our holistic coding phase, one analyst began by reviewing all transcripts and inductively coding the data with a phrase indicating the espoused beliefs and the differences between the students' experiences and the intent of or potential within SL pedagogy. These differences indicate, whether implicitly or explicitly, the beliefs held by undergraduate students about engineering. This resulted in an initial list of 105 codes. Next, the codes that were similar to one another were grouped and renamed. For example, the codes "SL course is more real-world engineering than engineering courses" and "SL courses are more openended and real-world experiences" were grouped into one code that was renamed "SL more realworld than engineering courses." This grouping resulted in 59 unique codes (shown in the 
International Journal for Service Learning in Engineering, Humanitarian Engineering and Social Entrepreneurship Vol. 16, No. 2, pp. 14-38, Fall 2021

ISSN 1555-9033

Appendix). These codes, subsequently referred to as underlying assumptions, were used in the next analysis phase to support the theming of the data.

Next, the team performed the theming for data analysis. Theming the data allowed us to categorize the underlying assumptions into themes and then interpret the meaning of the themes through creating rich descriptions of the participants' experiences. ${ }^{66} \mathrm{In}$ our case, the themes were the overarching categories of implicit beliefs held by undergraduate students within the SL context. To determine our themes, we performed iterations to distill the codes (the underlying assumptions) from the holistic coding phase into a set of overarching beliefs. Two analysts worked independently to develop the themes: one analyst used a bottom-up approach by grouping the 59 codes into similar ideas that were ranked by significance in the data set, a judgment made based on the combination of the frequency of occurrence and the way the theme was salient or emotionally significant for the participants; the second analyst used a top-down approach to group the 59 codes based on the claims from prior literature. After each iteration, the two analysts met to discuss their thematic categories, including how they overlapped and how they differed, and interpretations of the corresponding excerpts. After the final iteration, each analyst had a list of overarching themes, under which key underlying assumptions were described based on the 59 holistic codes and their excerpts. These lists were compared, and the analysts discussed them with the entire authorship team to receive feedback and additional perspective and agreement on the meaning of the data to arrive at a consensus. This process strengthened communicative validation; through this process, we learned from each other to strengthen our understanding of the students' experiences and associated implicit beliefs.

Ultimately, the theming of the data phase resulted in a set of implicit beliefs (categories of underlying assumptions) that students hold about engineering in SL contexts. The final list of the 59 holistic codes (underlying assumptions), their mapping to the themes (implicit beliefs), the frequencies of the codes (number of excerpts), and the number of interviews and focus groups in which the code was present are available in Table III in the Appendix. The themes are further supported excerpts that represent the espoused beliefs (what students were saying) and provide rich descriptions for each theme to understand how the beliefs manifested, presented in the Results below. Thus, the findings are a set of implicit beliefs, along with how the students' implicit beliefs manifested in their experiences of engineering SL.

\section{RESULTS}

The data analysis resulted in three main themes that are the implicit beliefs held by undergraduate engineering students about engineering: (1) Engineering is predominantly technical, (2) Engineering requires deliverables/tangible products, and (3) Engineers are the best problem solvers. These three themes also indicate gaps between the outcomes of these students' SL experiences and the potential embedded in SL pedagogy. While these themes are characteristic of engineering broadly, they are centered in differing areas, such that theme 1 centers on underlying beliefs about engineering as a discipline/field, theme 2 centers on beliefs about engineering pedagogy, and theme 3 centers on beliefs about the students' role as engineers working with the community. When reviewing the excerpts for each implicit belief theme and its underlying assumptions, we found that these beliefs manifested problematically, in terms of how they affected engineering students' ability to achieve SL outcomes and make sense of their SL experience as a 
International Journal for Service Learning in Engineering, Humanitarian Engineering and Social Entrepreneurship Vol. 16, No. 2, pp. 14-38, Fall 2021

ISSN 1555-9033

departure from their core engineering courses. However, we also found that these beliefs also manifested in a positive way, such that some students were able to disrupt these beliefs internally, becoming aware of and adjusting their own ways of thinking about engineering. The results below explore how each of the three themes is manifested through excerpts that describe the belief, how the belief about engineering is problematic in SL contexts, and how students disrupted the belief. In this section, we address RQ1 through the discussion of these themes; we address RQ2 within each sub-section's description of how each belief is manifested in engineering SL contexts.

\section{Engineering is predominantly technical}

The first theme, the implicit belief that engineering is predominantly technical, is supported by a variety of underlying assumptions that demonstrate students believe engineering is predominantly comprised of math, science, problem solving, computer programming, and/or other technical skills. Students also believe that engineers do not know how to communicate with others, that the community has a technical problem to be solved, and that emotion does not support engineering solutions. The following excerpt from a student in the domestic garden SL course shows an example of how this belief manifests in engineering SL:

Honestly, [I] feel like a lot of people don't think about things like this [e.g., reading and other non-technical course assignments], in terms of, engineering. A lot of engineering, I think, is revolved around what's the next tech? What's the next iPhone? Or like, who is going to come up with the next best car? And I think it's not something that's really talked about when kids are going into engineering. In my head, engineering was always like, Oh, the next best, like, medical product or a computer, coding, stuff like that. And I think just taking a step back and realizing what else engineering can be applied to. (Domestic Garden Interview: Female, First year, Chemical Engineering, Bi-racial)

In the above excerpt, the student details what they believe engineering is and is not based on what they were taught as a kid, specifically designing the "next tech" and using computer programming, and shows how they apply this definition in the SL context.

However, believing that engineering is predominantly technical can be problematic when students are in a SL context, especially when they do not consider other non-technical elements when designing a solution, such as the context and knowledge of the community. For example, they assume that the community's problems can be solved by only a technical skill or that engineering solutions need to utilize technical skills only, rather than being informed by and enhanced through empathy and emotion. In the design challenge as part of a course that supports humanitarian engineering scholars, students were tasked with designing a new, innovative shelter for homeless people by utilizing the resources available to the homeless. When speaking about how the assignment connects to SL, a student from this design challenge said:

Like, I personally, when you're thinking humanitarian, you know, like helping those who are less fortunate and along the lines of that. So I was taking cost into consideration because these people don't really, because I think the way their living quarters are set up is not the first thing on their mind. Probably having a meal or something like that. For me, as an engineer, I think it's fixing something that, fixing a situation that's not ideal but helping them fix it with their resources that they can get. So you could use trash bags if they can get trash bags from the dumpster, which isn't really ideal but they could. And things or supplies that we took. They can help with their living situations with easy things that you 
International Journal for Service Learning in Engineering, Humanitarian Engineering and Social Entrepreneurship Vol. 16, No. 2, pp. 14-38, Fall 2021

ISSN 1555-9033

can get that you don't have to have a whole bunch of money or stuff to do. (In-Class Design Challenge Focus Group: Female, Humanitarian Engineering Scholar, Black)

In this quote, the student suggests that solely their technical skills are what is needed in order to "fix" an issue that homeless people experience. From a technical perspective, obtaining resources from the trash might suffice, however the student struggles to recognize the ways that using a trash bag from a dumpster to build a shelter affects a person's dignity. This limited consideration highlights a gap: the student has not fully considered the non-technical factors, placing the engineering solution as priority and downplaying the significance of emotion and human dignity. This excerpt also reveals the student's assumptions about the issues of homeless people, such as the types of resources they have access to and whether they prioritize food over shelter.

Conversely, some students' interview data suggest they recognize the potential harm in the belief that engineering is predominantly technical. For example, a student from the same design challenge course recognized the importance of compassion and care when designing technical solutions:

I think to be a good engineer, you have to walk in the shoes of other people. I think to be a good person you have to walk in the shoes of other people. I think especially with designing things, or creating things, applying math and science to problems in this world we have to consider the human aspect of the work that we do, because it's more than just the math and the science. It's, you know engineers are creating things for people. We, in this world, this world is...A lot of the problems that we have to solve are for people, because we live in this world. (In-Class Design Challenge Interview: Male, Engineering Undeclared / Humanitarian Engineering Scholar, First year, White)

The student acknowledges that, in addition to the solution itself, engineers also need to consider the situations of the people for whom they are designing. Furthermore, the student has extrapolated what he has learned in this specific SL experience to change his view of engineering, recognizing that there is not only room for empathy and human consideration, but that these are essential elements of the field. Even though the student is using technical skills to design a solution, they understand that the final product will be used by people, and therefore must incorporate the knowledge, skills, and needs of the community in the solution.

\section{Engineering requires deliverables/tangible products}

The second theme, the implicit belief that engineering requires deliverables/tangible products, is supported by the following underlying assumptions: engineering courses are focused on grades; engineering courses are structured with learning objectives that students must complete for educational advancement; engineering students must deliver a project at the end of the course that solves a problem; and engineering students focus on activities they can put on their resumes. To demonstrate how this theme manifests in SL, we present an excerpt from an interview with a student who participated in a SL course that partners with an international orphanage. During this course the students were assigned projects for the orphanage, such as building an aquaponics system, that they designed and implemented in-country; in the interview, the student explained how it was expected that they would have to develop a working prototype to receive an ' $A$ ' in the course:

Because I think if you give everything that you have, you're giving your best effort and you fulfill all of the, you know, physical expectations, whether it be reports or a working 
International Journal for Service Learning in Engineering, Humanitarian Engineering and Social Entrepreneurship Vol. 16, No. 2, pp. 14-38, Fall 2021

ISSN 1555-9033

prototype or attendance every day, I think you should get an 'A.' (International Orphanage Interview: Female, Biomedical Engineering, Third year)

Through her comment, this student details her perception of the learning objectives for the course: reports, prototypes, and attendance. These objectives are focused on the deliverables and other tangible products - the "physical expectations"-typical in engineering courses. She also communicates an additional expectation that if the students complete all these objectives, that they should automatically receive a good grade in the course which highlights how this student considers SL courses to be different from traditional engineering courses, even though they are expecting to deliver typical engineering products.

This belief that engineering requires deliverables/tangible products is problematic in the SL context because it hinders the student's ability to achieve broader SL outcomes, such as supporting the community's needs; instead, it places the student's emphasis on developing the product that needs to be delivered for them to earn their grade. This emphasis appears again later in the same student's interview where they explain that they were not concerned if their project failed:

I would feel bad on behalf of them [the community] if our system failed because we built it for them. But I think we actually saw quite a few of the projects that had been there before and they seemed to kind of have been used for a time and kind of run their course. So I think maybe the people there are kind of used to it. (International Orphanage Interview: Female, Biomedical Engineering, Third year)

In this excerpt, the student recognizes that their project will not be a sustainable solution for the community. However, they are not as concerned with their project lasting long-term because their main goal for the course is to complete a project. The data also suggest an additional problematic belief: the student assumed that the community is used to the projects failing. Even still, they have no qualms about continuing the same trend-producing a deliverable to achieve the course learning outcome-regardless of whether it creates lasting change for the community.

Despite focusing on class deliverables, some students demonstrated focus on the communityoriented SL outcomes and the community's needs. In the domestic garden SL course, the students were split into two groups that were designing and developing either a farming robot or a solar generator, respectively. A student from this domestic garden SL course realized how their role goes beyond these projects, saying:

So this class has helped that along because we weren't really going into it as we need to get the solar job. We need to get the solar generator started, we need to get the [farming robot] done. Even [though] those were projects, we were there to help support that community garden. We were there to go in and help support them, and help them...not better themselves but use what we're doing to help continue on the good work that they're doing. (Domestic Garden Focus Group: Male, Agricultural Engineering)

This excerpt shows that the student recognizes that they are there to support the community's needs, rather than simply redefining a problem in order to create an engineering solution. The student understands that while they can apply their engineering skills to the problem, they are ultimately prioritizing the community's needs by taking a supporting role, regardless of what the finished product is. While this student has been able to disrupt the belief that engineering needs to produce deliverables, this quote's emphasis on the community's "using what we're doing" hints at the next theme, that engineers are the best problem solvers. 
International Journal for Service Learning in Engineering, Humanitarian Engineering and Social Entrepreneurship Vol. 16, No. 2, pp. 14-38, Fall 2021

ISSN 1555-9033

\section{Engineers are the best problem solvers}

The third theme is the implicit belief that engineers are the best problem solvers. As it arose in the data, this theme is undergirded by the following underlying assumptions: engineers have the right skills and mindset to design solutions to problems; engineers should be the primary decision makers; engineers are diligent and hard-working; engineers can solve society's problems; and engineers' efforts will result in a positive impact on the community. This theme is demonstrated in an interview excerpt from a student from the international orphanage SL course:

But as an engineer we really got the opportunity to implement sustainable solutions at a location that needed help, which I think is something that is unique to engineers is the fact that we can logically think through these designs and put into place sustainable things that will hopefully last because we designed them all and we have the engineering knowledge. (International Orphanage Focus Group: Female, Biomedical Engineering, First year, White)

Here, the student asserts that engineers are the ones that can create sustainable designs because they "have the engineering knowledge," implying that those without engineering knowledge would not be able to design a sustainable solution. Furthermore, this also demonstrates the belief that engineering students have privileged knowledge needed to solve a problem for a group in need.

We can see another instance of how the belief that engineers are the best problem-solvers manifests problematically in the follow excerpt. A student from the domestic garden SL course describes how they perceive their direct interactions with the community:

'Cause all the work that I've done for this class, that I've put into this class, is benefiting people already. It's showing them hope, it's showing them encouragement. It's driving them to continue what they're doing, and putting up a good fight. [The community garden leader] has had to work so hard to get this community garden off the ground and had to work around legislation and city officials and city councils and things like that. And so that we're here doing this work for her, and helping her along the way, I feel like it's giving her hope. (Domestic Garden Focus Group: Male, Agricultural Engineering)

Even though the community garden leader has already put in hard work into the project and is familiar with the needs of the community, this student suggests that the community would not be able to succeed without the help of the engineering students in the course. By emphasizing and focusing on how engineers provide the solutions the community needs, the student downplays the community leader's efforts and overlooks the community's existing knowledge about the situation. According to this student, even though the community leader and garden have received acclaim for their successes, it is the implementation of the farming robot and student presence that will provide hope for the community, highlighting engineering students' problem solving abilities. This student believes the engineering support they have provided the community garden, in the brief time they have spent in the course, is giving this community hope and motivation to continue. This statement suggests the community would not have done so if the students did not become involved in the project, which perpetuates the underlying assumption that society's problems can be solved (only?) with engineering skills.

Although priority of engineering skills to solve problems was a persistent belief, other students have realized that the project depends on more than just this ability. For example, another student from the same domestic garden project said: 
International Journal for Service Learning in Engineering,

Humanitarian Engineering and Social Entrepreneurship

Vol. 16, No. 2, pp. 14-38, Fall 2021

ISSN 1555-9033

And so it was just to see that, it's not just [the community garden leader] that's invested in this cause, or it's not just our little class that...there's a lot backing this project or this garden. It was pretty impactful to see how much consideration goes into every single step. Yeah. So we can't just come in [and] assume that we know the best options or anything. (Domestic Garden Focus Group: Female, Fifth year, White)

This quote demonstrates that students are able to disrupt the belief that engineers are the best problem solvers, and recognize that engineers may not know the best solution. This student is respectful of the hard work the community has already put into the project and recognizes that the project's success depends on more than just the students' engineering expertise. The student is learning from the community leader about what solution is best for the community.

\section{DISCUSSION AND IMPLICATIONS}

The three themes resulting from our analysis describe implicit beliefs about engineering held by undergraduate students within engineering SL contexts. These beliefs have manifested in ways that are problematic, such as perpetuating harmful stereotypes, as well as in ways that are disruptive. We use the term "disruptive" to describe when students' demonstrate an ability to be critically aware and even resist or reject-the problematic elements of their own beliefs. These disruptions provide evidence of critical reflection. ${ }^{67} \mathrm{~A}$ "disruptive" approach to SL would encourage students to develop and embrace perspectives about engineering that promote justiceor equity-oriented outcomes, moving SL toward better alignment between the potential of this pedagogy for transformation and its current implementation. This research does not suggest by use of the term "disruption" that students demonstrate the ability to be change agents in the status quo or the larger system or context of SL; the disruption we refer to is understood as something internal to the participants in terms of their awareness and reaction to the beliefs that we found implicit in the data set. Instead, we suggest the implicit belief is momentarily disrupted, that instances arise in which the ways engineering students are commonly socialized are questioned, the belief is resisted, and/or an alternative, more nuanced/critical belief is demonstrated. These findings present, perhaps, opportunities for creating moments of awareness that can be leveraged towards student learning outcomes. Beliefs, both problematic and disruptive, can impact the SL contexts and the extent to which SL can achieve deeper and transformational outcomes.

The problematic manifestations of these beliefs align with findings from other research on why SL pedagogy in engineering struggles to reach theoretical outcomes and may exacerbate social injustices. Nieusma and Riley ${ }^{17}$ presented two primary assumptions made by engineers within efforts designed to promote development in community contexts: 1) technological functionality and products are centered; and 2) project ownership, power relations, and the role of community are less important than technical products. Furthermore, these authors find these assumptions have implications on both community contexts that involve engineering students as well as more broadly in the engineering profession. ${ }^{17}$ Niles et al. ${ }^{68}$ found that engineering students have difficulty justifying the value of non-technical work and its relevance to engineering, and that this difficulty extends to challenges with prioritizing and integrating community perspectives and knowledge into projects. In addition to reinforcing this earlier work, our findings also demonstrate that SL experiences can support students' ability to actively disrupt problematic beliefs. In this section, we discuss the implications of the problematic and disrupted beliefs, as well as their impact 
International Journal for Service Learning in Engineering, Humanitarian Engineering and Social Entrepreneurship Vol. 16, No. 2, pp. 14-38, Fall 2021

ISSN 1555-9033

on the outcomes of SL in engineering. Based on our results, we provide recommendations for both instructors and students so that they may 1) prevent manifestation of problematic in actions and behaviors in the context of SL courses and 2) anticipate and disrupt more readily potentially problematic beliefs before they negatively impact SL and engineering contexts more broadly.

\section{Discussion on belief that engineering is predominantly technical}

The belief that engineering is predominantly technical can be problematic in engineering SL because it can isolate students from engaging with the social and political elements associated with the SL context and pedagogy. Engineering does require a high level of technical proficiency. But $\mathrm{Cech}^{58}$ argues that depoliticization (e.g., seen in our data as 'engineers only do math and science') in engineering cultures positions social justice issues in ways that make them seem peripheral to or irrelevant to the work of engineers. Such framing is supported by a predominant focus on technical elements in traditional engineering coursework; together, these can foster development of "apolitical" SL experiences in which root causes of social challenges are not addressed and are seen by students as outside the scope of the course objectives. In reality, the technical challenges faced by many of the local community partners in SL are merely a symptom of larger social and political challenges. Engineering cultures and practices are both technical and socio-political. ${ }^{69}$ Absent a robust discussion of the social or political challenges faced by these communities, engineering students perceive the technical problems arising from the sociopolitical challenges as the sole target of their work. With their root causes unaddressed, the community challenges are likely to persist. ${ }^{70}$ Furthermore, overemphasizing technical skills can impede engineers' growth and ability to communicate and engage with community members in a meaningful manner. Downplaying the importance of interpersonal skills and positioning engineering problems as outside the sociopolitical sphere contributes to the distancing of the engineering students from the contextual SL factors in which they work; this distance then perpetuates, rather than deconstructs, a larger engineering culture, where its inherent social and political elements are consistently downplayed and deprioritized.

When participants disrupted the belief that engineering is predominantly technical, students embraced the idea that engineering involves work beyond developing a technical solution, especially when that work aims to support a community through solving a problem. Students who could disrupt the dominant belief of technical predominance valued the SL context for providing an authentic real-world experience: they valued learning how engineering intersects with other areas of society and understood how such knowledge could benefit them in their future job after graduation. Beyond this utilitarian perspective, ${ }^{71}$ some students mentioned how the SL experience supported their desire to seek employment with engineering companies that promote and/or contribute to strong civic responsibility. These students acknowledgements of the social and political context highlight the value of non-technical skills and underscore engineering students' ability to develop these skills in SL contexts; these reports from students also demonstrate the benefits of SL approaches in engineering that address the underlying socio-political factors that create the need for service within communities. Furthermore, the community also benefits when students consider its socio-political contexts, particularly when that consideration results in technical and social solutions designed to address the community's specific challenges.

In order to support the disruption of this belief - that engineering solutions are purely technical - within SL in engineering, we recommend that SL instructors acknowledge and use materials to introduce students to the social and political contexts that create the need for the 
service in the partner community; ${ }^{24}$ this approach to SL would also highlight the socio-technical nature of engineering ${ }^{69}$ by explicitly teaching and valuing non-technical elements of engineering. ${ }^{72}$ Students in SL can develop technical knowledge while, at the same time, they can learn the professional skills critical to success in the engineering workforce. ${ }^{73}$ Professional skill development does not need to be an impediment to acquiring technical skills. The ability to consider the needs of customers soliciting products and solutions is essential to engineering. ${ }^{74}$ To actively dispel the erroneous belief that engineering is predominantly technical, SL courses should highlight the implications of these solutions in the real-world. Therefore, engineering students must be supported in first recognizing the social and political elements of engineering and how these intersect with the SL context. To accomplish this, instructors can incorporate assessments and use rubrics that explicitly highlight the evolution of student attitudes and motivations, ${ }^{75}$ and the aspects of the SL context, engineering solution, and approach that are non-technical. ${ }^{8}$ Collectively, these recommendations can support SL that seeks to address the root causes that create a community's need for service, while preparing engineers who understand the social implications of their efforts.

\section{Discussion on belief that engineering requires deliverables/tangible products}

The belief that engineering requires deliverables/tangible products can manifest problematically in SL in that it pressures students to produce an engineering solution at the expense of other outcomes that could benefit the students as well as the community. Students often explicitly link outcomes such as completing course requirements, receiving a good grade, and achieving degree requirements to completing their SL projects. In addition to these pressures, artificial time parameters (e.g., a semester) are also imposed on the project. These factors help explain why students in SL courses place emphasis on completing and delivering a tangible engineering solution, but in doing so they jeopardize the quality, scope, and relevance of the solutions they deliver to the community.

Producing an engineering solution, or any other form of positive community impact, requires time. ${ }^{70}$ Short-term SL is often too brief to benefit the community or even achieve significant student learning outcomes ${ }^{76}$. In addition to time, appropriately solving a community challenge through a SL project requires a deep understanding of the social and political nature of the community's challenges and needs. ${ }^{27}$ As implemented, most SL is unlikely to appropriately solve a community need in a short amount of time. While programs in engineering offer opportunities to engage in SL projects that are not constrained to a single semester, ${ }^{77}$ the timeframe to implement projects within SL courses is often limited to a semester, and students focus on the product they must complete within this window. In these scenarios, students may struggle with leaving work undone, as they are socialized to complete tasks as assigned and on time. Because of these constraints, engineering solutions from SL efforts can fail in the long-run, and sometimes immediately ${ }^{78}$ In many instances, students have come to expect and accept that they may be delivering a project that is incomplete or unlikely to succeed. But low quality and misaligned projects can jeopardize the community's goals and position the community, for students, as a living lab/classroom rather than an equitable partner.

SL instructors can support students' ability to disrupt this implicit belief by expanding the course focus: rather than placing priority on delivering a product, instructors can help students recognize that supporting the community to collaboratively develop a solution can be a part of the student role within SL. Students who embrace this perspective and role recognize there are 
International Journal for Service Learning in Engineering, Humanitarian Engineering and Social Entrepreneurship Vol. 16, No. 2, pp. 14-38, Fall 2021

ISSN 1555-9033

multiple ways they can create a positive impact on the partner community. In fact, scholars argue that in order to achieve deeper and lasting impact, SL must be embedded in authentic partnerships. $^{24,27}$ SL experiences that emphasize deliverables do so at the expense of time that could be used to engage the community toward building authentic relationships. ${ }^{24}$ Time spent with community members, whether children, adults, or elderly - even if it is uncomfortable at firstcan provide interpersonal growth opportunities, contribute to higher education and understanding of different lived experiences, and foster other experiences valuable and relevant to engineering. Students can make contributions here if they understand that relationship building is part of the project objective and is necessary for developing an engineering solution that will help the community create a long-lasting, sustainable solution suitable to their needs. This disruption of the students' belief that engineering requires a product allows them to not just focus on their grade, but to actively engage with the community, thereby promoting a deeper form of SL. ${ }^{27}$

Instructors can further help students disrupt the problematic nature of this belief by emphasizing that the students' grades do not rely on the delivery of an engineering solution. They can support students shift in perspective through engaging course materials that emphasize the need for relationship building ${ }^{79}$ and explicitly address the limitations of time requirements in SL contexts. Instructors should emphasize to students that focusing on achieving results within the timeframe at the expense of relationships will result in an unsustainable project that only partially addresses the needs of the community. Assignments and associated rubrics can be adjusted to evaluate the development of professional skills, the promotion of authentic relationships, and a deep understanding of the community context. Furthermore, instructors can emphasize the importance and value of interpersonal dynamics within SL and how these may mirror elements of professional engineering. ${ }^{80,81}$ This could be incorporated into the course through reflections and other means to allow students to think proactively about how to continue incorporating the human aspect of engineering throughout their engineering courses beyond SL contexts. ${ }^{82,83}$ Students can be led to expect and accept that timelines for positive impact do not follow a semester calendar.

\section{Discussion on belief that engineers are the best problem solvers}

The belief that engineers are the best problem solvers is problematic in SL contexts because it can promote a university- or student-centric form of SL in which the involvement of the community is limited. When students hold this belief, they may not recognize the value of incorporating the knowledge, skills, and needs of the community, perhaps even believing those assets are unnecessary to solve the problem. Prior research has found that engineers often hold the belief that they can solve any problem, and they have greater self-sufficiency and superior ability to solve problems when compared to other academic groups. ${ }^{84}$ Furthermore, engineering students often believe that what they do is harder than other disciplines and suggest that their motivation to be an engineer is not to change the world, but instead to secure a comfortable lifestyle. ${ }^{85}$ This belief is further evidenced in Cech's ${ }^{58}$ findings, where meritocracy (e.g., 'engineers achieve technical solutions through innate ability and hard work') in engineering cultures supports the framing of social justice issues as irrelevant to the work of engineers. Students who hold these beliefs may then implement designs and solutions that they believe the community wants, justifying this assumption on the hard work required to obtain engineering skill sets. Without valuing diverse perspectives in SL contexts, engineering students may not understand the implications of their designs on people and the broader context. ${ }^{69}$ Similarly to sacrificing solution efficacy in service of adhering to the time frame of the semester, the belief that engineers are the best equipped to solve 
International Journal for Service Learning in Engineering, Humanitarian Engineering and Social Entrepreneurship Vol. 16, No. 2, pp. 14-38, Fall 2021

ISSN 1555-9033

problems can help perpetuate a SL pedagogy that is student- or university-centric, in which the community becomes a context and not a partner.

To disrupt the problematic elements of this belief, students must learn to value community partners' expertise and experiences, as well as how these can be drawn on to support solutions. Students should be encouraged to consider aspects of both the engineering design and the community context that lie outside a student's abilities, particularly how community perspectives can be included throughout the project. ${ }^{86}$ When students challenge this belief in SL contexts, they acknowledge that the community has a rich expertise about the problem contexts and solutions, that students are only a part of the contribution, and that the perspective of others must be valued. Instructors can also support the development of stronger abilities to integrate community expertise within the approach to the solution.

Instructors can promote students' abilities to understand and value the community's role in solving local challenges by explicitly incorporating and highlighting the importance of community contributions across elements of the SL class. Human- and user-centered approaches ${ }^{2}$ and empathy ${ }^{79,87,88}$ can be promoted to encourage students to include those that will be affected by the service efforts. Furthermore, instructors can invite community partners to help shape curricula, offer lectures and instruction, and create other in-and out-of-class activities to highlight the breadth of expertise they hold about their local context. In general, instructors can model for students the extent to which community knowledge is relevant, and how it can be leveraged within an effective partnership to address community needs. Furthermore, instructors should offer opportunities for students to reflect on how they can apply this knowledge of incorporating other perspectives and viewpoints to their future engineering coursework and careers.

Intersections across the implicit beliefs held by engineering students in SL

While we have described them independently here, the beliefs we have presented can interact with one another. For example, engineering is predominantly technical informs both engineering requires deliverables, where a technical problem is a fixable, discrete problem, and engineers are the best problem solvers, where engineers hold the technical knowledge and therefore can fix the problem. Nieusma and Riley ${ }^{17}$ also observed that engineering students tended to focus more on technical functionality and producing a product than meaningfully engaging the communities and prioritizing their perspectives. Further, these beliefs appeared to be interconnected within our data in an additional way, indicating that when disrupted, only one belief may be disrupted at the time. That is, if a student disrupted one belief, another was still implicitly held in a problematic way.

Therefore, we recommend that instructors recognize that students enter SL with a wide variety of interconnected beliefs. Instructors should work to surface and challenges these beliefs. Awareness of beliefs can minimize the chances problematic beliefs are transmitted implicitly and stand in direct contrast to the explicitly stated goals of the SL effort.

\section{Limitations and Future Work}

While our dataset is small, with four focus groups and four interviews for a total of eight units of analysis, this included a total of 20 participants representing $20 \%$ of the total number of students engaging in the SL courses. The smaller focus group and interview setting allowed us to create an environment in which students were comfortable sharing their experiences. Additionally, the interviews allowed us to ask deeper questions regarding particular students' experiences. While 
International Journal for Service Learning in Engineering,

Humanitarian Engineering and Social Entrepreneurship

Vol. 16, No. 2, pp. 14-38, Fall 2021

ISSN 1555-9033

we were unable to interview all students that participated in the focus groups, we selected interview participants to balance the diversity of background and perspectives to strengthen the transferability of results.

When selecting representative quotes in our Results section, we purposefully chose three quotes for each of the three implicit beliefs: one defining the implicit belief, one showing how the implicit belief is problematic in engineering SL contexts, and one showing how students are disrupting the problematic belief. Each quote was selected independently to best demonstrate our results. While we recognize that not all participants and cases were represented by quotes in the results, they were not intentionally excluded to omit data that would contradict our interpretations. Even though not all cases were represented in this paper, each case did reinforce our findings as our resulting themes were prevalent across our entire dataset.

Furthermore, the protocol used to interview the focus group and interview participants was designed for a larger study and, therefore, did not explicitly ask about students' beliefs. However, per our justification in the Data Collection section for its use, the implicit beliefs of engineering students in SL contexts emerged in the data analysis. In future work, we will work toward designing a study and protocol focused on beliefs, including both implicit and explicit, for engineering students in SL contexts to continue to build on the findings in this paper.

\section{CONCLUSION}

This empirical investigation revealed the implicit beliefs held by undergraduate engineering students in service-learning contexts. Our findings lead to three implications, of which both educators and students should be mindful. First, beliefs held by students about engineering are shown to impact SL in various ways. Some of the implicit beliefs manifest problematically, while in some cases elements from the SL context may allow students to disrupt the dominant beliefs about engineering. We have highlighted three beliefs about engineering and the role of engineers made by students that are salient in SL contexts - engineering is predominantly technical, engineering requires deliverables/tangible products, and engineers are the best problem solvers and we have shown how these beliefs have implications for SL as pedagogy in engineering. These student beliefs may reinforce and perpetuate the ways engineering SL continues to be implemented in ways that center the university and student; these approaches to SL pedagogy are depoliticized and do not pursue solutions to the root causes of social or socio-technical challenges. While SL pedagogy does show potential to support transformation in community contexts, ${ }^{24,31}$ it appears SL in engineering is bounded and limited by implicit beliefs held by students about engineering. If problematic beliefs are allowed to persist in SL and in engineering more broadly, humanitarian, social, and equity-oriented efforts will remain compartmentalized into discrete sub-disciplinary silos, rather that incorporated as an integral aspect of the engineering profession. At the same time, this research produces evidence that students are also disrupting these problematic beliefs, which highlights the potential of SL pedagogy. Together, students and instructors can limit the impact problematic beliefs have on SL and support students in ways that better prepare them to address issues of justice and equity in their professional lives. Moving forward, increasing emphasis on surfacing the beliefs held by students and working towards disrupting and minimizing problematic beliefs can support further transformational SL. Additionally, SL instructors should learn about these beliefs, receive support so that they are not perpetuating or embedding these problematic beliefs into their course designs, and teach students to deconstruct these beliefs. Revealing and 
International Journal for Service Learning in Engineering, Humanitarian Engineering and Social Entrepreneurship Vol. 16, No. 2, pp. 14-38, Fall 2021

ISSN 1555-9033

promoting reflection on these dominant beliefs can inform recommendations for how both instructors and students can be supported in deconstructing inherent notions of SL in engineering to support this pedagogy in being a transformational pedagogy that lives up to its potential.

\section{ACKNOWLEDGMENT}

This article is based on work supported by the National Science Foundation under grant 1821866. The opinions and content expressed are those of the authors and do not necessarily reflect the views of the National Science Foundation. The authors would like to thank each of the CBL contexts including the instructors, community partners, and students involved.

\section{REFERENCES}

1 George D. Kuh, "High-Impact Educational Practices: What They Are, Who Has Access to Them, and Why They Matter," Washington, D.C., (2008).

2 Carla B. Zoltowski, William C. Oakes, and Monica E. Cardella, "Students' Ways of Experiencing HumanCentered Design," Journal of Engineering Education, 101, no. 1, (2012), 28-59, [Online]. Available: http://www.scopus.com/inward/record.url?eid=2-s2.084856684272\&partnerID $=40 \& m d 5=697 \mathrm{a} 0 \mathrm{beae} 84351 \mathrm{~d} 19721 \mathrm{a} 6 \mathrm{c} 4 \mathrm{acb} 2 \mathrm{dfdd}$.

3 N. Dukhan, M. R. Schumack, and J. J. Daniels, "Implementation of Service-Learning in Engineering and its Impact on Students' Attitudes and Identity," European Journal of Engineering Education, 33, no. 1, (2008), 21-31, doi: 10.1080/03043790701746132.

4 Marybeth Lima, William C. Oakes, and John L. Gruender, Service-learning: Engineering in your community. Wildwood, MO: Great Lakes Press, (2006).

5 Lina D. Dostilio, The Community Engagement Professional in Higher Education: A Competency Model for an Emerging Field. Stylus Publishing, LLC, (2017).

6 Aditya Johri and Barbara M. Olds, Cambridge Handbook of Engineering Education Research. New York, NY: Cambridge University Press, (2014).

7 William Oakes, Carla B. Zoltowski, and James Huff, "Engineering Service-Learning: A Model for Preparing Students for Engineering Practice While Meeting Needs of the Underserved," Journal of Engineering Education Transformations, 27, no. 4, (2014), 46-56.

8 Angela R. Bielefeldt, Kurtis G. Paterson, and Christopher W. Swan, "Measuring the Value Added from Service Learning in Project-Based Engineering Education," International Journal of Engineering Education, 26, no. 3, (2010), 535-546.

$9 \quad$ Angela R. Bielefeldt and Nathan Canney, "Impacts of Service-Learning on the Professional Social Responsibility Attitudes of Engineering Students," International Journal for Service Learning in Engineering, Humanitarian Engineering and Social Entrepreneurship, 9, no. 2, (2014), 47-63, doi: 10.24908/ijsle.v9i2.5449.

10 Lori Pompa, "Service-Learning as Crucible: Reflections on Immersion, Context, Power, and Transformation," Michigan Journal of Community Service Learning, Fall, (2002), 67-76.

11 Mark Chesler and Carolyn Vasques Scalera, "Race and Gender issues Related to Service-Learning Research," Michigan Journal of Community Service Learning, Special Is, (2000), 18-27.

12 Jerusha Conner and Joseph Erickson, "When Does Service-Learning Work? Contact Theory and ServiceLearning Courses in Higher Education," Michigan Journal of Community Service Learning, 23, no. 2, (2017), 53-65, doi: 10.3998/mjcsloa.3239521.0023.204.

13 Dan W. Butin, "The Limits of Service-Learning in Higher Education," Review of Higher Education, 29, no. 4, (2006), 473-498, doi: 10.1353/rhe.2006.0025.

14 Alexander W. Astin and Linda J. Sax, "How Undergraduates Are Affected by Service Participation," Journal of College Student Development, 39, no. 3, (1998), 251-263.

15 Caroline Baillie, Engineers within a local and global society, 1, no. 1. (2006).

16 Jon A. Leydens and Juan C. Lucena, "Social Justice: A Missing, Unelaborated Dimension in Humanitarian Engineering and Learning Through Service," International Journal for Service Learning in Engineering, 
International Journal for Service Learning in Engineering, Humanitarian Engineering and Social Entrepreneurship Vol. 16, No. 2, pp. 14-38, Fall 2021

ISSN 1555-9033

Humanitarian Engineering and Social Entrepreneurship, 9, no. 2, (2014), 1-28, doi: 10.24908/ijsle.v9i2.5447. no. 1. (2010).

18 David J. Weerts and Lorilee R. Sandmann, "Building a Two-Way Ttreet: Challenges and Opportunities for Community Engagement at Research Universities," Review of Higher Education, 32, no. 1, (2008), 73-106, doi: 10.1353/rhe.0.0027.

19 Ernest L. Boyer, "Scholarship Reconsidered: Priorities of the Professoriate," Princeton, NJ, (1990).

20 Mark G. Chupp and Mark L. Joseph, "Getting the most out of service learning: Maximizing student, university and community impact," Journal of Community Practice, 18, no. 2, (2010), 190-212, doi: $10.1080 / 10705422.2010 .487045$.

21 Amy Driscoll, Barbara Holland, Sherril Gelmon, and Seanna Kerrigan, "An Assessment Model for ServiceLearning: Comprehensive Case Studies of Impact on Faculty, Students, Community, and Institution," Michigan Journal of Community Service Learning, Fall, (1996), 66-71.

22 Robert G. Bringle and Julie A. Hatcher, "Campus-Community Partnerships: The Terms of Engagement," Journal of Social Issues, 58, no. 3, (2002), 503-516, doi: 10.1111/1540-4560.00273.

23 Lorrie George-Paschal, "Investigating the Overlapping Experiences and Impacts of Service-Learning: Juxtaposing Perspectives of Students, Faculty, and Community Partners," Michigan Journal of Community Service Learning, 25, no. 2, (2019), doi: 10.3998/mjcsloa.3239521.0025.203.

24 Tania Mitchell, "Traditional vs Critical Service Learning," Michigan Journal of Community Service Learning, (2008), 50-65.

25 Sue Ellen Henry and M. Lynn Breyfogle, "Toward a New Framework of ' Server' and 'Served ': De ( and Re ) constructing Reciprocity in Service-learning Pedagogy," International Journal of Teaching and Learning in Higher Education, 18, no. 1, (2006), 27-35, [Online]. Available: http://www.isetl.org/ijtlhe/.

26 Lina D. Dostilio, "Community Engagement, Civic Learning, and the Spiritan Charism," Spiritan Horizons, 9, no. 9, (2014), 137-142. Available: https://dsc.duq.edu/spiritan-horizons/vol9/iss9/21/

27 Peter M. Miller and Madeline M. Hafner, "Moving toward Dialogical Collaboration: A Critical Examination of a University- School-Community Partnership," Educational Administration Quarterly, 44, no. 1, (2008), 66110, doi: 10.1177/0013161X07309469.

28 Douglas Barrera, Lauren N. Willner, and Keali'i Kukahiko, "Assessing the Development of an Emerging Critical Consciousness through Service Learning," Journal of Critical Thought and Praxis, 6, no. 3, (2018), doi: $10.31274 /$ jctp-180810-82.

29 Roni Strier, "The Construction of University-Community Partnerships: Entangled Perspectives," Higher Education, 62, no. 1, (2011), 81-97, doi: 10.1007/s10734-010-9367-x.

30 Jessica V Barnes et al., "Creating and Sustaining Authentic Partnerships with Community in a Systemic Model," Journal of Higher Education Outreach and Engagement, 13, no. 4, (2009), 15-29.

31 Patti H. Clayton, Robert G. Bringle, and Mary Morrison, "Differentiating and Assessing Relationships in Service-Learning and Civic Engagement: Exploitative, Transactional, or Transformational," Michigan Journal of Community Service Learning, Spring, (2010), 5-22.

32 Jude Butcher, Michael Bezzina, and Wendy Moran, "Transformational Partnerships: A New Agenda for Higher Education,” Innovative Higher Education, 36, no. 1, (2011), 29-40, doi: 10.1007/s10755-010-9155-7.

33 Kayhan Parsi and Justin List, "Preparing Medical Students for the World: Service Learning and Global Health Justice," Medscape Journal of Medicine, 10, no. 11, (2008), 268.

34 Carla J. Groh, Lynda G. Stallwood, and John J. Daniels, "Service-Learning in Nursing Education: Its Impact on Leadership and Social Justice," Nursing Education Perspectives, 32, no. 6, (2011), 400-405.

35 Linda Plitt Donaldson and Laura Daughtery, "Introducing asset-based models of social justice into service learning: A social work approach," Journal of Community Practice, 19, no. 1, (2011), 80-99, doi: 10.1080/10705422.2011.550262.

36 Meryl Nadel, Virginia Majewski, and Marilyn Sullivan-Cosetti, Social Work and Service Learning: Partnerships for Social Justice. Lanham, MD: Rowman \& Littlefield Publishers, Inc., (2007).

37 John Duffy, Edmund Tsang, and Susan Lord, "Service-learning in engineering: What why and how?," (2000).

38 Tania D. Mitchell, David M. Donahue, and Courtney Young-Law, "Service Learning as a Pedagogy of Whiteness," Equity and Excellence in Education, 45, no. 4, (2012), 612-629, doi: $10.1080 / 10665684.2012 .715534$.

39 Sam Marullo and Bob Edwards, "From Charity to Justice: The Potential of University-Community 
International Journal for Service Learning in Engineering, Humanitarian Engineering and Social Entrepreneurship Vol. 16, No. 2, pp. 14-38, Fall 2021

ISSN 1555-9033

Collaboration for Social Change," American Behavioral Scientist, 43, no. 5, (2000), 895-912, doi: $10.1177 / 00027640021955540$.

40 Michael H. Connors and Peter W. Halligan, "A Cognitive Account of Belief: A Tentative Road Map," Frontiers in Psychology, 5, no. February, (2015), 1-14, doi: 10.3389/fpsyg.2014.01588.

41 Martin Fishbein and Icek Ajzen, Predicting and changing behavior: The reasoned action approach. New York, NY: Taylor \& Francis, (2011).

42 Deanna Kuhn, The Skills of Argument. New York, NY: Cambridge University Press, (1991).

43 Steven Sloman and Philip Fernbach, The knowledge illusion: Why we never think alone. New York, NY: Penguin, (2018).

44 Aaron C. T. Smith, Cognitive Mechanisms of Belief Change. Melbourne, Victoria, Australia: Springer, (2016).

45 Jan Nespor, "The Role of Beliefs in the Practice of Teaching," Journal of Curriculum Studies, 19, no. 4, (1987), 317-328, doi: 10.1080/0022027870190403.

46 M. Frank Pajares, "Teachers' Beliefs and Educational Research: Cleaning Up a Messy Construct," Review of Educational Research, 62, no. 3, (1992), 307-332, doi: 10.3102/00346543062003307.

47 Glenda S. Stump, Jenefer Husman, and Marcia Corby, "Engineering Students' Intelligence Beliefs and Learning,” Journal of Engineering Education, 103, no. 3, (2014), 369-387, doi: 10.1002/jee.20051.

48 Sarah-Jane Leslie, Andrei Cimpian, Meredith Meyer, and Edward Freeland, "Expectations of Brilliance Underlie Gender Distributions across Academic Disciplines," Science, 347, no. 6219, (2015), doi: 10.4135/9781483392240.n8.

49 Elizabeth A. Canning, Katherine Muenks, Dorainne J. Green, and Mary C. Murphy, "STEM Faculty who Believe Ability is Fixed have Larger Racial Achievement Gaps and Inspire Less Student Motivation in their Classes," Science Advances, 5, no. 2, (2019), doi: 10.1126/sciadv.aau4734.

50 Jihn-Chang J. Jehng, Scott D. Johnson, and Richard C. Anderson, "Schooling and Students' Epistemological Beliefs about Learning," Contemporary Educational Psychology, 18, no. 1, (1993), 23-35.

51 Theresa Conefrey, "Sexual Discrimination and Women's Retention Rates in Science and Engineering Programs Sexual Discrimination and Women's Retention Rates in Science and Engineering Programs," Feminist Teacher, 13, no. 3, (2001), 170-192.

52 Jacqueline Rohde et al., "Anyone, but not Everyone: Undergraduate Engineering Students' Claims of Who Can Do Engineering,” Engineering Studies, (2020), 1-22, doi: 10.1080/19378629.2020.1795181.

53 Emily Dringenberg, Amy Kramer, and A. Betz, "Smartness as a Cultural Practice in Engineering Education: Undergraduate Students' Shared Beliefs," Journal of Engineering Education, (under review).

54 George S. Bridges and Sara Steen, "Racial Disparities in Official Assessments of Juvenie Offenders: Attributional Stereotypes as Mediating Mechanisms," American Sociological Review, 63, no. 4, (1998), 554570.

55 Robin DiAngelo, “White Fragility," International Journal of Critical Pedagogy, 3, (2011), 54-70, doi: $10.1051 / \mathrm{tsm} / 201204014$.

56 Eduardo Bonilla-Silva, Racism without Racists: Color-Blind Racism and the Persistence of Racial Inequality in America [New Chapter on the Obama Phenomenon], Fifth. Rowman \& Littlefield, (2010).

57 Diane Lynn Gusa, "White Institutional Presence: The Impact of Whiteness on Campus Climate," Harvard Educational Review, 80, no. 4, (2010), 464-489, doi: 10.17763/haer.80.4.p5j483825u110002.

58 Erin A. Cech, "The (Mis)Framing of Social Justice: Why Ideologies and Depoliticization and Meritocracy Hinder Engineers' Ability to Think about Social Justice," in Engineering Education for Social Justice: Critical Explorations and Opportunities, 10, J. Lucena, Ed. Golden, CO: Springer, (2013).

59 Joachim Walther, Michael A. Brewer, Nicola W. Sochacka, and Shari E. Miller, "Empathy and Engineering Formation," Journal of Engineering Education, 109, no. 1, (2020), 11-33, doi: 10.1002/jee.20301.

60 Giselle Guanes, Linjue Wang, David Delaine, and Emily Dringenberg, "Empathic approaches in engineering capstone design projects: student beliefs and reported behaviour," European Journal of Engineering Education, (2021), 1-17.

61 Michelle Madsen Camacho, "Power and Privilege: Community Service Learning in Tijuana Dimensions of Subjectivity," Michigan Journal of Community Service Learning, (2004), 31-42.

62 Danielle Endres and Mary Gould, "'I am also in the position to use my Whiteness to help them out': The communication of Whiteness in service learning," Western Journal of Communication, 73, no. 4, (2009), 418436, doi: 10.1080/10570310903279083.

63 John W. Creswell, Research Design: Qualitative, Quantitative and Mixed Methods Approaches, 4th ed. 
International Journal for Service Learning in Engineering, Humanitarian Engineering and Social Entrepreneurship Vol. 16, No. 2, pp. 14-38, Fall 2021

ISSN 1555-9033

Thousand Oaks, CA: SAGE Publications, Inc., (2014).

64 Joachim Walther, Nicola W. Sochacka, and Alice L. Pawley, "Data Sharing in Interpretive Engineering Education Research: Challenges and Opportunities from a Research Quality Perspective," Advances in Engineering Education, 5, no. 2, (2016), 1-16.

65 Clifford Geertz, ""From the Native's Point of View ": On the Nature of Anthropological Understanding," Bulletin of the American Academy of Arts and Sciences, 28, no. 1, (1974), 26-45.

66 Johnny Saldaña, The Coding Manual for Qualitative Researchers, 3rd ed. Thousand Oaks, CA: SAGE Publications, (2015).

67 Sarah L. Ash and Patti Clayton, "Documenting Learning: The Power of Critical Reflection in Applied Learning," Journal of Applied Learning in Higher Education, 1, no. 1, (2009), 25-48, [Online]. Available: http://www.missouriwestern.edu/\%5Cnappliedlearning/journal/Ash \& Clayton, Generating, Deepening, $\% 5$ Cnand Documenting Learning.pdf.

68 Skye Niles, Santina Contreras, Shawhin Roudbari, Jessica Kaminsky, and Jill Lindsey Harrison, "Resisting and Assisting Engagement with Public Welfare in Engineering Education," Journal of Engineering Education, 109, no. 3, (2020), 491-507, doi: 10.1002/jee.20323.

69 Andrea Mazzurco and Scott Daniel, "Socio-Technical Thinking of Students and Practitioners in the Context of Humanitarian Engineering," Journal of Engineering Education, 109, no. 2, (2020), 243-261, doi: $10.1002 /$ jee. 20307.

70 Randy Stoecker, Liberating Service Learning and the rest of Higher Education Civic Engagement. Philadelphia, Pennsylvania: Temple University Press, (2016).

71 Kristin L. Gunckel and Sara Tolbert, "The Imperative to Move toward a Dimension of Care in Engineering Education," Journal of Research in Science Teaching, 55, no. 7, (2018), 938-961, doi: 10.1002/tea.21458.

72 Larry J. Shuman, M. Besterfield-Sacre, and Jack McGourty, "The ABET 'Professional Skills' - Can They Be Taught? Can They Be Assessed?," Journal of Engineering Education, 94, no. 1, (2005), 41-55.

73 Kaitlin Litchfield, Amy Javernick-Will, and Andrew Maul, "Technical and Professional Skills of Engineers Involved and Not Involved in Engineering Service," Journal of Engineering Education, 105, no. 1, (2016), 70 92, doi: $10.1002 /$ jee.20109.

74 Merlijn Kouprie and Froukje Sleeswijk Visser, "A Framework for Empathy in Design: Stepping Into and Out of the User's Life," Journal of Engineering Design, 20, no. 5, (2009), 437-448.

75 Barbara E. Moely, Sterett H. Mercer, Vincent Ilustre, Devi Miron, and Megan McFarland, "Psychometric Properties and Correlates of the Civic Attitudes and Skills Questionnaire (CASQ): A Measure of Students ' Attitudes Related to Service-Learning," Michigan Journal of Community Service Learning, Spring, no. 2000, (2002), 15-26.

76 Elizabeth Tryon, Randy Stoecker, Amy Martin, Kristy Seblonka, Amy Hilgendorf, and Margaret Nellis, "The Challenge of Short-Term Service-Learning," Michigan Journal of Community Service Learning Spring, no. 2000, (2008), 16-26.

77 William Oakes, James Huff, Carla B. Zoltowski, and Devendra Canchi, "Impact of the EPICS Model for Community-Engaged Learning and Design Education," International Journal of Engineering Education, 34, no. 2, (2018), 734-745.

78 Amy E. Wood and Christopher A. Mattson, "Design for the Developing World: Common Pitfalls and How to Avoid Them," Journal of Mechanical Design, 138, no. 3, (2016), 1-11, doi: 10.1115/1.4032195.

79 Nicola Sochacka, Joachim Walther, Shari Miller, and Kathryn Youngblood, "Facilitating Empathic Communication Modules in Undergraduate Engineering Education: A Handbook," (2020). [Online]. Available: http://eeti.uga.edu/wp-content/uploads/2019/02/ Empathy-Modules-Workbook_2020_v3.pdf.

80 Lori Simons and Beverly Cleary, "The Influence of Service Learning on Students' Personal and Social Development," College Teaching, 54, no. 4, (2006), 307-319, doi: 10.3200/CTCH.54.4.307-319.

81 Patrick L. Yorio and Feifei Ye, "A Meta-Analysis on the Effects of Service-Learning on the Social, Personal, and Cognitive Outcomes of Learning," Academy of Management Learning and Education, 11, no. 1, (2012), 927, doi: $10.5465 /$ amle.2010.0072.

82 Julie A. Hatcher and Robert G. Bringle, "Reflection: Bridging the Gap between Service and Learning," College Teaching, 45, no. 4, (1997), 153-158, doi: 10.1080/87567559709596221.

83 J. Beth Mabry, "Pedagogical Variations in Service-Learning and Student Outcomes," Michigan Journal of Community Service-Learning, no. May 1998, (1998), 41.

84 Elizabeth Godfrey and Lesley Parker, "Mapping the Cultural Landscape in Engineering Education," Journal of 
International Journal for Service Learning in Engineering,

Humanitarian Engineering and Social Entrepreneurship

Vol. 16, No. 2, pp. 14-38, Fall 2021

ISSN 1555-9033

Engineering Education, 99, no. 1, (2010), 5-22.

85 Reed Stevens, Daniel Amos, Andrew Jocuns, and Lari Garrison, "Engineering as Lifestyle and a Meritocracy of Difficulty: Two Pervasive Beliefs among Engineering Students and their Possible Effects," (2007), doi:

10.18260/1-2--2791.

86 Christopher A. Mattson and Amy E. Wood, "Nine Principles for Design for the Developing World as Derived from the Engineering Literature," Journal of Mechanical Design, Transactions of the ASME, 136, no. 12, (2014), doi: 10.1115/1.4027984.

87 Justin L. Hess and Nicholas D. Fila, “The Manifestation of Empathy within Design: Findings from a ServiceLearning Course," CoDesign, 12, no. 1-2, (2016), 93-111.

88 Linjue Wang, Turhan Kendall Carroll, and David A. Delaine, "A Pilot Study of the Development of Empathy within a Service-Learning Trip from a Qualitative Perspective," ASEE Annual Conference and Exposition,

Conference Proceedings, 2018-June, (2018).

\section{APPENDIX}

TABLE III

List of 59 holistic codes representing the underlying assumptions that support the implicit beliefs along with the number of excerpts and number of interviews and focus groups in which the code was present

\begin{tabular}{|c|c|c|c|}
\hline Implicit Beliefs and Underlying Assumptions & $\begin{array}{c}\# \\
\text { Excerpts } \\
\end{array}$ & $\begin{array}{c}\# \\
\text { Interviews }\end{array}$ & $\begin{array}{c}\# \\
\text { FGs } \\
\end{array}$ \\
\hline \multicolumn{4}{|l|}{ Engineers are the best problem solvers } \\
\hline $\begin{array}{l}\text { Assumed SL class projects more real-world than } \\
\text { engineering class projects }\end{array}$ & 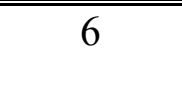 & 1 & 2 \\
\hline Assuming needs of the people/community & 19 & 4 & 3 \\
\hline Assumptions about societal issues/diversity & 6 & 1 & 1 \\
\hline Community would not be involved in project & 4 & 1 & 0 \\
\hline Design/projects would work as in the classroom & 4 & 1 & 2 \\
\hline Engineering can impact the world & 1 & 1 & 0 \\
\hline Engineers know the best solution & 1 & 0 & 1 \\
\hline Engineers should build simple/cheap designs & 1 & 0 & 1 \\
\hline Government isn't doing enough to address social issues & 2 & 1 & 0 \\
\hline HE can have local as well as international impact & 2 & 2 & 0 \\
\hline Only engineers could help & 2 & 1 & 1 \\
\hline Personal interest to help others & 2 & 2 & 0 \\
\hline Project designs are focused on hardships/negative aspects & 1 & 1 & 0 \\
\hline Purpose of engineering is to help other people & 4 & 0 & 1 \\
\hline $\begin{array}{l}\text { Put more effort into project that directly impacts } \\
\text { someone }\end{array}$ & 6 & 1 & 3 \\
\hline Recognizing privilege & 17 & 3 & 4 \\
\hline SL has long-term impact on community & 1 & 0 & 1 \\
\hline
\end{tabular}




\begin{tabular}{|c|c|c|c|}
\hline Implicit Beliefs and Underlying Assumptions & $\begin{array}{c}\# \\
\text { Excerpts }\end{array}$ & $\begin{array}{c}\# \\
\text { Interviews }\end{array}$ & $\begin{array}{c}\# \\
\text { FGs }\end{array}$ \\
\hline $\mathrm{SL} / \mathrm{HE}$ benefits both engineers and community/people & 3 & 2 & 1 \\
\hline $\begin{array}{l}\text { Students would not be engaging/building relationships } \\
\text { with the community }\end{array}$ & 3 & 1 & 2 \\
\hline Traditional engineering only impacts $10 \%$ of people & 8 & 3 & 2 \\
\hline \multicolumn{4}{|l|}{ Engineering requires deliverables/tangible products } \\
\hline $\begin{array}{l}\text { Assumption about how much of the project can be } \\
\text { accomplished in one semester; the extent of the impact is } \\
\text { limited }\end{array}$ & 1 & 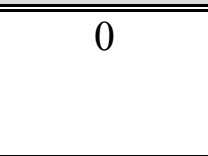 & 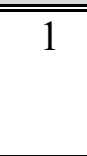 \\
\hline $\begin{array}{l}\text { Doing it for a grade; how SL should be graded; SL/HE is } \\
\text { easy grade }\end{array}$ & 8 & 2 & 1 \\
\hline $\begin{array}{l}\text { Expectations of engineers: study a lot, work a lot, put SL } \\
\text { on resume, volunteer }\end{array}$ & 10 & 2 & 2 \\
\hline $\begin{array}{l}\text { In SL/HE, can directly see impact of engineering } \\
\text { solutions as opposed to traditional engineering }\end{array}$ & 3 & 1 & 1 \\
\hline Instructors impact the course & 3 & 1 & 1 \\
\hline More effort needed for engineering than SL classes & 2 & 0 & 1 \\
\hline $\begin{array}{l}\text { People/community need their help to implement } \\
\text { solutions }\end{array}$ & 4 & 0 & 3 \\
\hline Project will fail after they leave & 5 & 1 & 1 \\
\hline SL and engineering aren't connected & 1 & 1 & 0 \\
\hline SL course more difficult than engineering course & 1 & 0 & 1 \\
\hline SL course more real-world than engineering & 7 & 2 & 1 \\
\hline SL courses more structured than engineering courses & 1 & 1 & 0 \\
\hline SL/HE course would be like an engineering course & 1 & 1 & 0 \\
\hline $\begin{array}{l}\text { Typical engineering class projects don't reflect the real- } \\
\text { world }\end{array}$ & 3 & 1 & 1 \\
\hline $\begin{array}{l}\text { Volunteering through SL is more impactful than } \\
\text { volunteering through other means }\end{array}$ & 1 & 1 & 0 \\
\hline \multicolumn{4}{|l|}{ Engineering is predominantly technical } \\
\hline $\begin{array}{l}\text { Assumptions about the engineering workplace/careers: } \\
\text { don't value service, plenty of jobs }\end{array}$ & 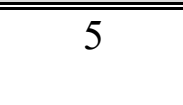 & 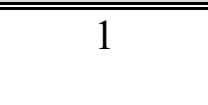 & 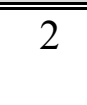 \\
\hline $\begin{array}{l}\text { Build better relationships with SL teammates than other } \\
\text { engineering classmates }\end{array}$ & 1 & 1 & 0 \\
\hline Can't learn SL lessons in an engineering class & 1 & 0 & 1 \\
\hline Difficulty working in new teams & 1 & 0 & 1 \\
\hline $\begin{array}{l}\text { Engineering design must keep the client/audience in } \\
\text { mind }\end{array}$ & 2 & 0 & 1 \\
\hline Engineering doesn't directly impact people & 3 & 1 & 2 \\
\hline $\begin{array}{l}\text { Engineering impacts the community but community } \\
\text { doesn't impact engineering }\end{array}$ & 1 & 1 & 0 \\
\hline
\end{tabular}




\begin{tabular}{|l|c|c|c|}
\hline Implicit Beliefs and Underlying Assumptions & $\begin{array}{c}\# \\
\text { Excerpts }\end{array}$ & $\begin{array}{c}\# \\
\text { Interviews }\end{array}$ & $\begin{array}{c}\# \\
\text { FGs }\end{array}$ \\
\hline $\begin{array}{l}\text { Engineering is math and science, problem solving, } \\
\text { programming, etc. }\end{array}$ & 6 & 1 & 3 \\
\hline Engineering students are role models for the community & 1 & 0 & 1 \\
\hline Engineering, SL, and real life are all connected & 4 & 1 & 1 \\
\hline Engineers don't communicate with people & 2 & 1 & 1 \\
\hline Engineers don't read & 2 & 1 & 0 \\
\hline Engineers don't show emotions & 1 & 1 & 0 \\
\hline Engineers learn applicable skills from SL & 1 & 1 & 0 \\
\hline $\begin{array}{l}\text { Engineers need to know how to communicate with } \\
\text { people }\end{array}$ & 5 & 2 & 2 \\
\hline $\begin{array}{l}\text { Impact of SL on engineering needs to be discussed in } \\
\text { engineering classroom }\end{array}$ & 1 & 1 & 0 \\
\hline Purpose of SL is personal and academic growth & 2 & 2 & 1 \\
\hline $\begin{array}{l}\text { SL doesn't prepare students to discuss community impact } \\
\text { / social issues }\end{array}$ & 1 & 0 & 1 \\
\hline SL is hands-on & 1 & 1 & 0 \\
\hline SL is not engineering & 1 & 0 & 1 \\
\hline SL is real-world application of engineering & 4 & 0 & 2 \\
\hline $\begin{array}{l}\text { SL only beneficial to engineering when it } \\
\text { impacts/involves people }\end{array}$ & 1 & 1 & 0 \\
\hline SL/HE in engineering curriculum is optional & 2 & 2 & 0 \\
\hline SL/HE not reality, not real job, not real engineering & 6 & 1 & 4 \\
\hline
\end{tabular}

